
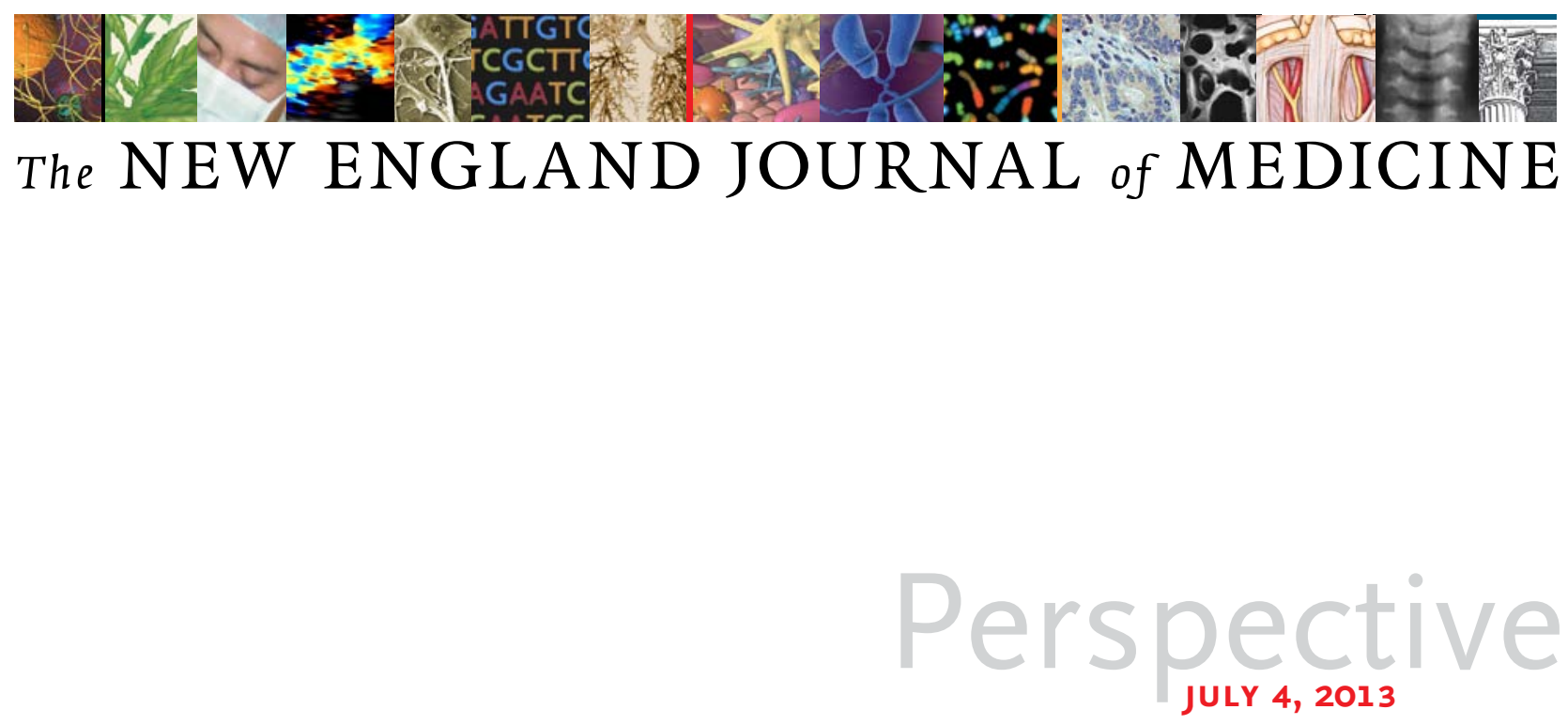

\title{
Can England's NHS Survive?
}

\author{
Nicholas Black, M.D.
}

\section{The past few months have witnessed the most 1 intense and prolonged criticism of England's National Health Service (NHS) in its 65-year histo- ry. Some critics have suggested that the NHS faces}

a crisis that can be resolved only by altering the fundamental principle on which it was founded - provision of funding from general taxation, with care being free at the point of use. Although the criticism was sparked by a February report on an inquiry into shortcomings at one hospital, ${ }^{1}$ the problems originated in 2010, when two profound forces were unleashed on the NHS: public-sector financial austerity and administrative reorganization. Together, these three factors have created the current turmoil.

Never before has the NHS had to cope with no increase in funding for a sustained period. With rising demand, the NHS is required to improve its productivity at an unprecedented rate of $4 \%$ per year. $^{2}$ The government is convinced that to achieve this improvement, two fundamental changes are needed.

The first concerns the local commissioning organizations that are responsible for purchasing hospital and community services for their geographically defined populations of 200,000 to $1 \mathrm{mil}-$ lion people. The 151 existing administrative bodies called Primary Care Trusts, which were led by nonclinical managers, have been replaced by 212 Clinical Commissioning Groups that are led by primary care doctors (general practitioners [GPs]) who, the government believes, will be more effective in controlling the use of the $£ 60$ billion (approximately $\$ 90$ billion) spent on secondary and community care services. (Spending on tertiary care — £20 billion [ $\$ 30$ billion] will be managed at a national level by a new entity called NHS England.) The second means of achieving better productivity is by increasing the competition among providers of hospital and community services through the greater use of non-NHS providers (including private for-profit, not-for-profit, and charity or volunteer organizations).

Prolonged financial stringency and a reorganization were challenging enough without a highprofile report suggesting that NHS hospitals may not be safe. ${ }^{1}$ The Francis Report on the inquiry into the Mid Staffordshire NHS Foundation Trust told a sad and troubling story of a hospital in which the humanity of care in some wards was appalling and in which the proportion of deaths deemed avoidable may have been higher than the $5 \%$ observed elsewhere in England and in other high-income countries. Despite uncertainty about the appropriateness of allowing public inquiries to influence policy, ${ }^{3}$ the government has responded by announcing sever- 
al initiatives: commitment to a simple single rating of the quality of a hospital (despite the fact that an independent expert review panel established by the government offered no encouragement for taking this approach ${ }^{4}$ ); a review of 14 other hospitals considered "suspect" on the basis of their standardized mortality ratios (despite the lack of validity of this measure ${ }^{5}$; a review of patient safety in the NHS, chaired by Donald Berwick; and the creation of a position for a chief inspector of hospitals to strengthen the existing quality regulator, the Care Quality Commission (despite a lack of evidence that regulation and inspection are effective mechanisms for improvement).

For the NHS to survive in its present form, it will need to overcome four formidable challenges. The first is financial constraint. Although the government claims to be maintaining funding in real terms, high rates of inflation in health care plus some financial maneuvers, such as withholding from the NHS any funds in its budget that it hasn't spent, mean there has been an actual funding reduction of almost 1\% per year since 2011. Of greater concern is that social services have undergone a substantial cut of about $7 \%$ per year since 2011 , which is resulting in more emergency admissions to hospitals and delays in discharges. These problems will be exacerbated if the new GP-led commissioners succeed in shifting some care from hospitals to more appropriate settings, since such a shift will further reduce the funds that hospitals receive. And overshadowing all these funding issues, the government's policy of protecting the level of health care spending is increasingly being questioned in Parliament by backbench members of the ruling party (i.e., those who do not occupy positions in government) who are unhappy about the repercussions that this protection has for other spending areas, such as defense and law enforcement. The final note of gloom is the growing realization that financial austerity seems to be set to continue beyond 2015 .

The second challenge is that the NHS may face opposition to its attempts to improve productivity. During the first 2 years of austerity, improvement was achieved mostly by freezing (or even reducing) staff pay, a policy that will not be sustainable. Similarly, driving down prices paid to suppliers for consumables cannot be extended indefinitely. In addition, professionals may oppose changes in working arrangements, such as requirements that hospital doctors work in the evenings and on weekends to boost the intensity of use of hospital facilities. But it's the more major initiatives to improve productivity, such as merging, downgrading, or closing hospitals, that will meet with the greatest opposition - not only from staff and the public, but also from politicians concerned about being reelected. And in the brave new world of markets, opposition to structural changes will even come from the economic regulator seeking to ensure that competition is maintained, regardless of its effect on the quality of care.

The third challenge is a lack of managerial capacity, stemming largely from the government's imposition of a reorganization that had little support from key staff members. This problem has been exacerbated by widespread criticism of managers, in the wake of the Francis Report, by members of the public, the media, and politicians. Although criticisms of some clinical and managerial staff were justified, wholesale condemnation was inappropriate and has contributed to the departure of some excellent managers (particularly when generous retirement options were available). The loss of managers is particularly apparent in the commissioning arena, where the effects will be intensified by the shifting of responsibility to GPs, most of whom will initially lack appropriate experience and training. Although they will receive technical help, it is unclear whether the initial enthusiasm of those GPs who have opted to take on this role will last. The honeymoon might end when GPs realize how uncomfortable it can be to ration care to patients and reduce funds for their local hospital.

Finally, there is concern that the way the NHS has been reorganized will impede attempts to achieve greater integration of services across health care and with social services - integration that is essential to achieving efficient, high-quality care.

So, will the NHS survive these challenges? There are three reasons for optimism. First, there are already examples of enterprising clinicians, managers, and politicians working together to reengineer their local services in imaginative ways. Second, despite legitimate concerns about the quality of some services, public support for the NHS is undiminished, as witnessed by the inclusion of a celebration of the NHS in the Olympics opening ceremony last July and as reflected in national surveys. Public enthusiasm is mirrored not only by that of most clinicians and managers but also by the majority of politicians (including the current gov- 
ernment, even if not by all its backbenchers). Though partly ideological, such support reflects the steady annual improvements in the NHS's effectiveness and safety seen in recent years. And third, turmoil provides an opportunity for innovation. It can produce collective efforts in which factional interests are set aside and long-standing controversial issues, such as bringing health care and social services closer together (even by combining their budgets into one), are finally addressed.

Although some of the challenges in England are unique, the underlying problem of meet- ing rising demand for care with steady or diminishing resources is faced by many countries. Just as we can learn from other health care systems, our experiences over the next few years in redesigning the organization and delivery of services will undoubtedly provide lessons for others.

Disclosure forms provided by the author are available with the full text of this article at NEJM.org.

From the Department of Health Services Research and Policy, London School of Hygiene and Tropical Medicine, London.

This article was published on June 19, 2013 , at NEJM.org.

1. Report of the Mid Staffordshire NHS
Foundation Trust public inquiry (Robert Francis, chair). Staffordshire, United Kingdom: Mid Staffordshire NHS Foundation Trust, February 2013.

2. Roberts A, Marshall L, Charlesworth A. A decade of austerity? The funding pressures facing the NHS from 2010/11 to 2021/22. London: Nuffield Trust, December 2012.

3. Black N, Mays N. Public inquiries into health care in the UK: a sound basis for policymaking? J Health Serv Res Policy 2013; 18:129-30.

4. Rating providers for quality: a policy worth pursuing? London: Nuffield Trust, March 2013.

5. Shahian DM, Wolf RE, lezzoni LI, Kirle L, Normand S-LT. Variability in the measurement of hospital-wide mortality rates. N Engl J Med 2010;363:2530-9. [Erratum, N Engl J Med 2011;364:1382.]

DOI: 10.1056/NEJMp1305771

Copyright @ 2013 Massachusetts Medical Society.

\title{
NICE: Moving Onward
}

\author{
Michael D. Rawlins, M.D.
}

T he National Institute for Clinical Excellence (NICE) was established in 1999, primarily to offer professionals in Britain's National Health Service (NHS) advice on providing care that meets the highest attainable standards. NICE's role was expanded in 2005 to include provision of analogous advice to the broader public health community on preventing ill health and maintaining good health. (The name was changed to the National Institute for Health and Clinical Excellence, but the acronym NICE has continued to be used.)

To meet these objectives, NICE now has three different strands of responsibilities (see table), ${ }^{1}$ and its budget from the government has increased tenfold. Much attention, however, continues to focus on NICE's technology appraisals and clinical-guideline programs.

Since 2000, the Institute has been publishing technology appraisals - assessments of the clinical effectiveness and costeffectiveness of (mainly) new pharmaceutical products, including whether providing them constitutes a good use of NHS resources. Contrary to popular mythology, NICE rejects less than $15 \%$ of technologies on the grounds of cost-ineffectiveness. In recent years, manufacturers have increasingly been offering the NHS, through NICE, "patient access schemes," which can substantially reduce the price of products and render them more likely to be considered cost-effective. Such offers have sometimes led a product with a negative provisional assessment to gain a positive final one, and occasionally decisions have been reversed because manufacturers have submitted additional evidence about a product's clinical effectiveness.

NICE's clinical guidelines improve the quality of care provided to NHS patients. For example, after the publication of a guide- line on the prophylactic use of antibiotics in patients with mechanical cardiac lesions, the volume of prescriptions by dental surgeons fell by more than $80 \%$ in 6 months. ${ }^{2}$ Similarly, as a result of a guideline on preventing venous thromboembolism, the rate of risk assessments in patients admitted to NHS hospitals increased from less than $40 \%$ in 2010 to $94 \%$ in 2012. ${ }^{3}$ Not all NICE's clinical guidelines have had such an effect: the Institute's guidance on managing infertility, including the use of in vitro fertilization, was fully adopted by only about $25 \%$ of primary care trusts (the regional administrative bodies that, until recently, commissioned and provided health care services to NHS patients).

NICE distinguishes clinical guidelines defining optimal care pathways for specific conditions from standards describing generic competencies for health care professionals. Professional standards 